
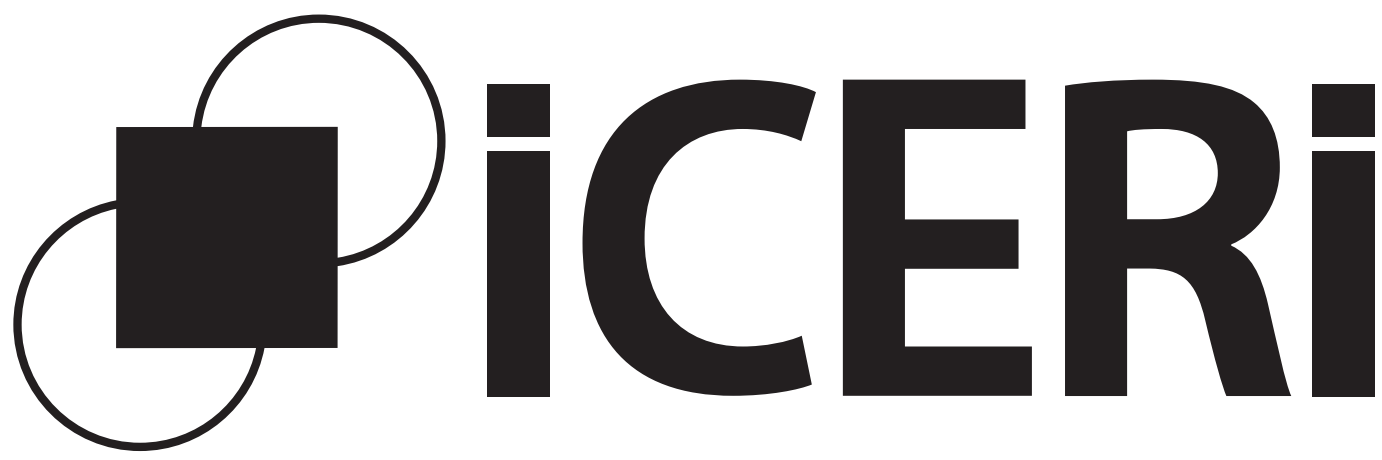

2018

IITH INTERNATIONAL CONFERENCE OF EDUCATION,

RESEARCH AND

INNOVATION
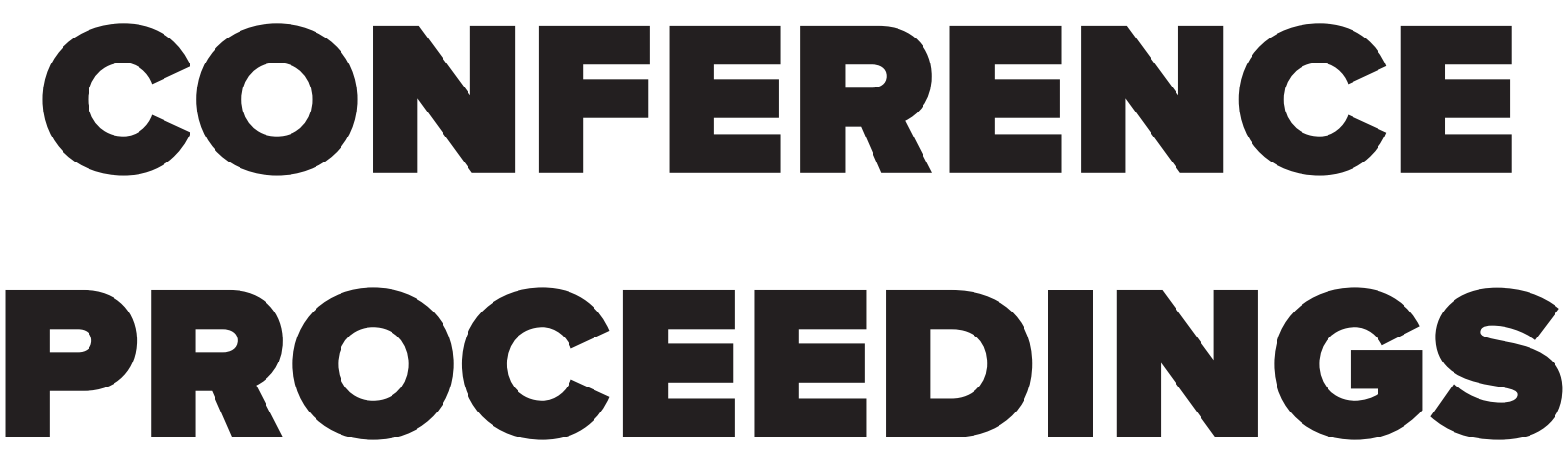

SEVILLE (SPAIN)

12-14 NOVEMBER 2018 
Published by

IATED Academy

iated.org

\section{ICERI2018 Proceedings}

11th International Conference of Education, Research and Innovation

November 12th-14th, 2018 - Seville, Spain

\section{Edited by}

L. Gómez Chova, A. López Martínez, I. Candel Torres

IATED Academy

ISBN: 978-84-09-05948-5

ISSN: 2340-1095

Depósito Legal: V-2884-2018

Book cover designed by

J.L. Bernat

All rights reserved. Copyright (C) 2018, IATED

The papers published in these proceedings reflect the views only of the authors. The publisher cannot be held responsible for the validity or use of the information therein contained. 


\title{
REPRESENTATION OF INDUSTRIAL PRODUCTS IN THE EARLY STAGES OF DESIGN: DRAWING AND ARTISTIC EXPRESSION IN INDUSTRIAL DESIGN
}

\author{
F. Felip, J.L. Navarro Lizandra \\ Universitat Jaume I (SPAIN)
}

\begin{abstract}
Hand drawing is a basic tool for industrial designers, as it allows them to represent and communicate concepts in an agile way during the initial design phase. Although we can find subjects related to drawing in the first years of all university degrees in industrial design, the way to implement the necessary activities is not always the most appropriate, and it may happen that, despite having practiced sketching, at the end of the course the students do not have the necessary skills to communicate their ideas effectively or adequately represent the reality that surrounds them.

This paper proposes twelve groups of activities designed to help industrial design students acquire skills related to hand drawing. The activities were implemented during the second course of the Degree in Industrial Design and Product Development Engineering at Universitat Jaume I, improving those implemented during the last course. The paper analyzes and discusses the positive results of the innovations introduced, which improved the mean grade of the course by $4.48 \%$ with respect to the grade obtained the previous year.
\end{abstract}

Keywords: Industrial design, drawing, sketching, product representations.

\section{INTRODUCTION}

Within industrial design education, freehand drawing is important because it stimulates creativity [1], develops sight-hand coordination [2] and is part of the cognitive process that designers use for problem solving [3]. For a correct learning process it is necessary to develop activities that are relevant, so that at the end of the course the students have the necessary skills to effectively communicate their ideas or adequately represent the objects that surround them.

The present work proposes a series of practical exercises grouped in 12 blocks, in which the aim is to practice the drawing of industrial products from direct observation, visual retention exercises, concepualization and synthesis exercises. In the past a similar methodology was implemented in the second year subject 'Artistic expression II' of the Degree in Industrial Design and Product Development Engineering at Universitat Jaume I, with positive results [4]. The methodology worked better than in previous years, and the students demonstrated that they had acquired the expected skills. However, some problems related to student fatigue were detected after the 3-hour practical sessions, the inadequacy of some real models used as a reference and the lack of time to complete some exercises.

For this course, some improvements have been introduced as a result of changes in the methodology and content of the exercises. This paper describes each of the exercises, analyses the results of their implementation in the current course, compares the results with those obtained in the previous course and discusses the improvements made. This paper describes each of the exercises, analyses the results of their application in the current academic year, compares the results with those obtained in the previous year and discusses the improvements made.

\section{METHODOLOGY}

\subsection{Description of the practical exercises implemented}

The last exercise of each block described below is a non-attendance activity that the students had to solve on their own outside the classroom. The rest are face-to-face practices to be carried out in the classroom. 


\subsubsection{PR1: analysis and interpretation of geometric volumes - 1}

- PR1-A: Interpretation of a mental image from a descriptive narration with geometric volumes. Linear perspective drawing with $2 \mathrm{~B}$ pencil on sketch paper.

- PR1-B: Formal reproduction through tactile experiences (geometric shapes). Linear perspective drawing with $2 \mathrm{~B}$ pencil on sketch paper.

- PR1-C: Interpreting the cylindrical volumes of the proposed model using prismatic shapes. Linear perspective drawing with 2B pencil on sketch paper.

- PR1-D: Conceptual interpretation of the practical exercise 1C from a new point of view. Linear perspective drawing with direct pen on sketch paper.

- PR1-E: Drawing of chiaroscuro of the model, in perspective (cylindrical shapes). 2B pencil on drawing paper (120-130 g).

- PR1-F: Puntillist interpretation in chiaroscuro from practical exercise 1F. No lines will be used in any case. Pen or fine-tipped and/or half-tipped marker on drawing paper (120-130 g). Colour: blue, brown or black.

\subsubsection{PR2: analysis and interpretation of geometric volumes - 2}

- PR2-A: Recognition of complex geometric shapes through tactile experiences. Linear perspective drawing with $2 \mathrm{~B}$ pencil or pen on sketch paper.

- PR2-B: Formal reproduction through tactile experiences (organic shapes). Linear perspective drawing with $2 \mathrm{~B}$ pencil or pen on sketch paper.

- PR2-C: Quick sketch of the proposed model. 2B pencil on sketch paper.

- PR2-D: Quick sketch from another point of view of the model proposed in practical exercise 2C. Direct pen on sketch paper.

- PR2-E: Interpreting the cylindrical volumes of the model analysed in practical exercise 2D using membranes or topological surfaces. Pencil 2B on sketch paper.

- PR2-F: Interpretation of the conceptualised model in practical exercise 2E using monochromatic chiaroscuro. Technique limited to pencil, charcoal or black pen on drawing paper (120-130 g).

\subsubsection{PR3: analysis of everyday objects: seesaw for children}

- PR3-A: Linear perspective drawing of the proposed model with 2B pencil on sketch paper.

- PR3-B: Linear drawing in perspective of the proposed model from another point of view. 2B pencil on sketch paper.

- PR3-C: Interpretation of the model from another point of view using chiaroscuro of linear paths. Fine and/or medium tip pen or dark-coloured pen on drawing paper (120-130 g).

- PR3-D: Free chromatic interpretation by means of visual textures (dots, strokes, etc.) or by means of flat inks from one of the points of view studied in practical exercises $3 A-B$. In this interpretation we can consider the redesign of the object, the change of colors or the introduction of a user to show its function. Markers, tempera or coloured pencils on multitechnical paper (160-300 g).

\subsubsection{PR4: analysis of everyday objects: taps and fittings}

- PR4-A: Linear perspective drawing of one of the models proposed with 2B pencil on sketch paper.

- PR4-B: Linear drawing in perspective of the same model as the practical exercise 4A from another point of view. Direct pen (blue or black) on sketch paper.

- PR4-C: Blurred monochromatic chiaroscuro of a different model. It is a question of interpreting the model as if it were neither metallic nor reflective, but as if it were made of a matt material. 2B pencil on drawing paper (120-130 g).

- PR4-D: Draw and design a new tap with different function (bathroom, bidet, kitchen, etc.) based on the same formal pattern as the tap of practical exercise 4B. It is a question of the designed object expressing its shape as part of a range of objects. 2B pencil, or pen on sketch paper. 
- PR4-E: Monochromatic interpretation using a single flat ink and a new point of view of the tap analysed in practical exercise. Marker, ink or tempera on multi-technical paper (160-300 g).

\subsubsection{PR5: analysis of everyday objects: packaging and/or household utensils}

- PR5-A: Quick sketch in perspective of one of the models proposed with a blue or black pen on sketch paper (120-130 g).

- PR5-B: Ergonomic studies: schematic sketching of the hand in two different positions. 2B pencil or pen on sketch paper.

- PR5-C: Ergonomic study of the object. Linear drawing of the object in perspective, together with the hand in a grasping or holding position from another point of view. Blue or black pen on sketch paper.

- PR5-D: Based on practical exercise 5C: new drawing in which the contour line of the object is reinforced with a medium or thick black marker, while the hand drawing should be outlined with a thinner marker or pen of the same colour to highlight the difference. In addition, the importance of the object should be enhanced by means of chromatic chiaroscuro. Multitechnical paper $(160-300 \mathrm{~g})$.

\subsubsection{PR6: analysis of everyday objects: electrical utensils}

- PR6-A: Linear perspective drawing of one of the models proposed with a blue or black pen on sketch paper.

- PR6-B: Linear drawing in perspective of the exploded cut of the model studied. 2B pencil on sketch paper.

- PR6-C: Sketch of a single orthogonal projection (the elevation or the profile) as a basic representation of a product. Drawing with marker or pen on drawing paper (120-130 g).

- PR6-D: Based on the PR6-C sketch: chromatic interpretation (can be traced) in order to generate volumetric sense. Markers, watercolours, tempera or coloured pencils on multitechnique paper (160-300 g).

\subsubsection{PR7: analysis of everyday objects: toys}

- PR7-A: Quick sketch in perspective of one of the models proposed with a blue or black pen on sketch or drawing paper (120-130 g).

- PR7-B: Quick sketch in perspective of another of the models proposed with a blue or black pen on sketch or drawing paper (120-130 g).

- PR7-C: Redesign of one of the models studied by means of chromatic chiaroscuro drawing in perspective. Free technique.

- PR7-D: Chromatic or monochromatic interpretation of the practical exercise 7C in order to represent its three-dimensional aspect, either by means of flat inks or by means of "render" type chromatic chiaroscuro. Markers, watercolours or watercolour pencils on multi-technique or marker-specific paper (160-300 g).

\subsubsection{PR8: analysis of everyday objects: vehicles}

- PR8-A: Expressive sketch of the object (car, motorcycle or tricycle) with blue or black direct pen on sketch paper.

- PR8-B: Chromatic or monochromatic (free choice) chiaroscuro in object perspective, from a different point of view than PR8-A, with 2B pencil on multi-technique paper (160-300 g).

- PR8-C: Design or redesign of a children's vehicle for the beach in chromatic chiaroscuro. Preliminary sketches must be submitted on sketch paper and the final design on multi-technique paper. Free expression technique.

\subsubsection{PR9: furniture and architecture}

- PR9-A: Expressive sketch of a lighting or furniture element. Ball pen and/or felt-tip pen on sketch paper. 
- PR9-B: Expressive sketch of a lighting or furniture element (a new point of view if it is the same object). Ball pen and/or felt-tip pen on sketch paper.

- PR9-C: Representation of the same furniture or lighting element integrated in the architectural environment in which it is located. HB or 2B pencil on sketch paper.

- PR9-D: Free chromatic interpretation of PR9-C, introducing the schematic image of a possible user of the object. Free technique.

\subsubsection{PR10: design of a mascot for an event or for a company}

- PR10-A: Design a mascot for an event or for a company (teamwork of three people). Set of linear and expressive drawings that represent the shape and nature of the character. Pencil, pen, or fine-tipped and/or half-tipped markers. Paper according to the chosen technique.

- PR10-B: The design and its elements will be presented on an A3 panel according to the specifications to be determined in time. Free technique of representation

\subsubsection{Exercises of abstraction, synthesis and formal schematization}

Each one is solved in class, after the end of the corresponding theory session:

1 Two visual retention exercises. 1a) Static visual retention exercise: drawing a static object without seeing it, through memory, after its image has been projected for one minute. Technique: pen on paper in A4 format. 1b) Dynamic visual retention exercise: draw an object that is displayed by turning in a loop after viewing the projection of its moving image for one minute. Technique: pencil (HB-2B) on paper in A4 format.

2 Space restitution exercise. Drawing an object in perspective through the vision of four photographs in orthogonal position (orthohedral projections) Technique: direct pen on paper in A4 format.

3 Exercise of conceptualization and use of the line. Select one of the six images offered and interpret it with a single stroke, without lifting the pen from the paper. Technique: direct pen on paper in A4 format.

4 Conceptualization and constructive synthesis exercise. Select one of the six images offered and interpret it by means of structured plans (structure drawing) to show the apparent volume of the object. The plans can't wrap around the shape. Technique: pencil (HB-2B), direct pen or finetipped marker on paper in A4 format.

5 Iconic conceptualization and synthesis exercise (infantilization). Select one of the six images offered and interpret it in such a way that its image is reduced to a more childlike image of the object, in order to be used for the design of a children's product (drawing for colouring, image for clothing, graphic design or a toy). Technique: direct pen or fine-tipped marker on paper in A4 format.

6 Iconic conceptualization and synthesis exercise (iconicity). Select one of the six images offered and interpret it in such a way that its level of iconicity is reduced to be used as a logo or brand of a company, institution or event. Technique: pencil (HB-2B), direct pen or fine-tipped marker on paper in A4 format.

7 Dynamic visual retention exercise. Draw an object that is displayed by turning it in a loop, considering the structure and shape by highlighting or enhancing the three-dimensionality with chiaroscuro. Technique: markers or coloured pencils on paper in A4 format.

8 Conceptualization and synthesis exercise (polyhedrization). Interpreting the volume through line and chiaroscuro of a human head through geometric planes trying to generate a polyhedral vision of the basic shape of the head. The model will be the partner himself/herself and, in a second phase, the turn to draw/be drawn will be exchanged. Technique: pen on paper in A4 format.

9 Conceptualization and synthesis exercise (caricaturing). Interpreting the image of a person's face by exaggerating features or caricaturing them in an attempt to generate a recognizable image of the portrayed/caricaturized person. The model will be the partner himself/herself and, in a second phase, the turn to draw/be drawn will be exchanged. Technique: pencil (HB-2B) on paper in A4 format. 
10 Exercise of conceptualization and synthesis of transformation (metamorphosis). Interpreting the metamorphosis between two different objects. At least three sequential transformation drawings must be made between the two different shapes of the objects. Technique: pencil (HB-2B) on paper in A4 format.

\subsubsection{Project}

- Phase 1: Design a product based on one of the topics proposed at the time. Preliminary sketches of different design alternatives. Free technique. A4 format.

- Phase 2: Design the compositional organization of the visual design panel with the established elements: product name, previous sketches, final design, orthogonal representations and explanatory text. Pencil and/or pencil on paper. A3 format.

- Phase 3: Development of the final design through several sketches from different points of view, sketches and renderings. Composition of the final panel showing the final design according to the instructions that will be indicated later. Free technique in the expression of the different visual elements. The final result must be combined by digital means (scanning and organising images using appropriate software) in order to be printed on A3 paper. Collages with clippings from the drawings will not be accepted.

\subsection{Comments on the changes made}

Because face-to-face practice sessions are focused on a single day a week in each lab group, when someone was unable to attend at their usual time for a justified reason, they could do so in another session of the same week.

The practice sessions lasted three hours in a row, and this entailed a certain fatigue in those monographic practices with similar thematic models. In order to solve this problem, in five practice sessions (from PR3 to PR7, both included), an informative intermission of in situ demonstrations of various artistic expression techniques, which are unusual in the field of expression and drawing in industrial design (charcoal, nib, watercolour, etc.), was held. Subsequently, the students were offered the means so that, optionally, those who wanted to experiment their skills with the new techniques could do an extra exercise.

PR6 used some real models of power tools whose weight and shape did not allow a good grip to be exposed in order to be observed for drawing. To improve their exposure and stability, the motors have been eliminated, leaving only the external casing without reducing their functional aspect, and new supports have been designed to place them in the most suitable positions for their study and observation.

The PR7 models were few or not very varied, so some new models specially designed for this practice have been introduced, taking into account more geometric concepts and basic shapes that allow a better visualization of the object and its proportions. This same practice has also included other types of models designed and built from pieces obtained from the recovery of discarded plastic bottles.

The PR9 used two low-volume office chairs as furniture models and two table lamps. Since the lack of volumetry in the case of the chairs had an impact on the difficulty of analysis and representative expression of the object in the drawings, the aim was to introduce new models with greater visibility of their elements and general structure. The two chairs have been replaced by a new, larger office chair and two hairdressing helmet dryers have been added, as well as a portable air-conditioning unit.

The last two weeks of the course were found to be complicated for the development of some activities in the previous course. For this reason, the last week of this course was used for the completion or improvement of some previous practical exercises.

\section{RESULTS}

There has been a high participation rate in all the activities developed, so the number of students who have passed the course in the first round has been very high: 82 of the 87 students enrolled $(94.25 \%)$. Of the five students who did not pass the course, only two had the opportunity to apply for the second round, as the other students dropped out of the course at the beginning and did not do any assessable work. The two students who were able to pass the course in the second round gave up and did not show up. 
The average grade for all the exercises was 7 points out of 10 , which is an increase of $4.48 \%$ with respect to last year's score.

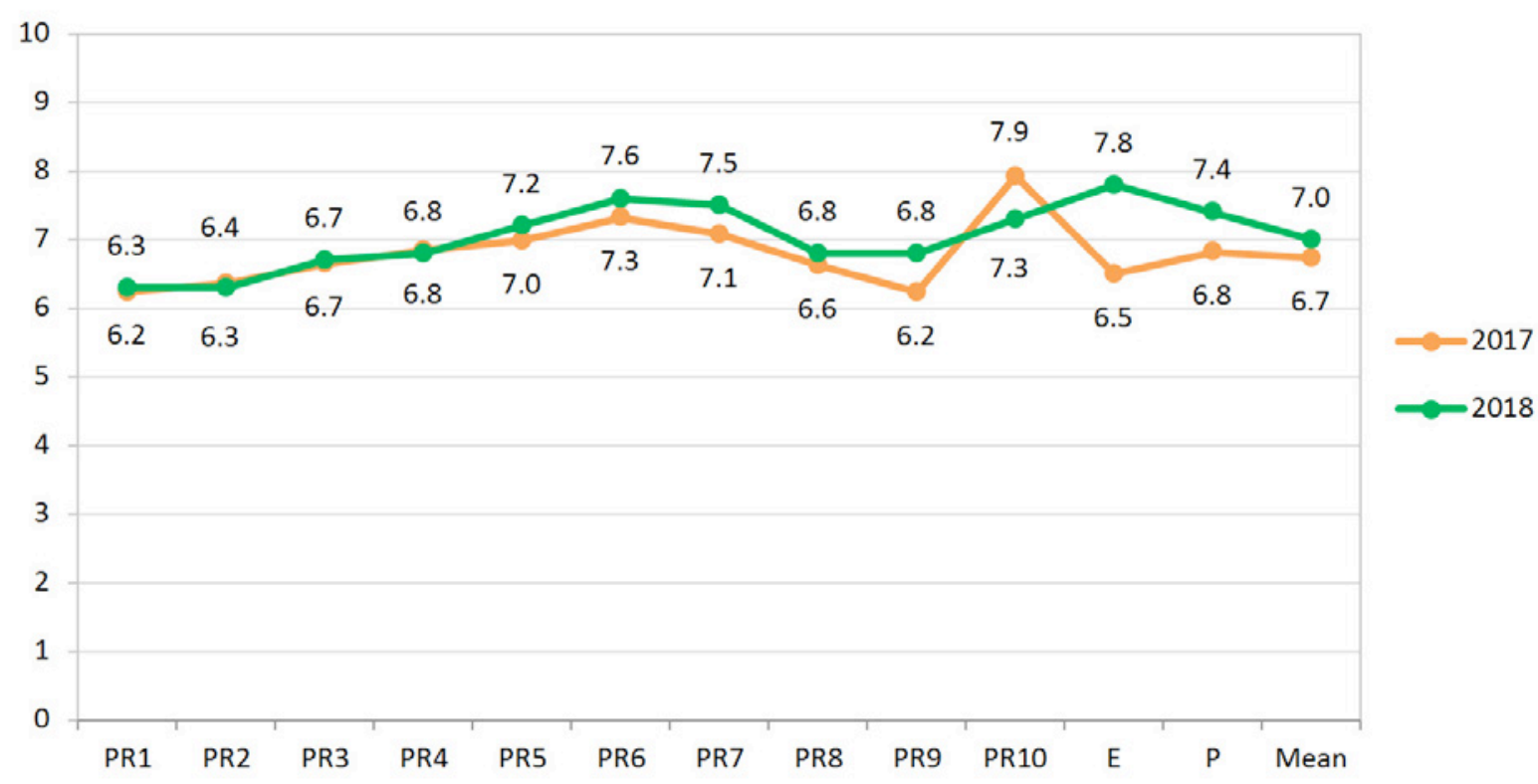

Figure 1. Average scores (PR1-PR10=practical exercises; $E=e x e r c i s e s$ of abstraction, synthesis and formal schematization; $P=$ project)

\section{DISCUSSION AND CONCLUSIONS}

In general, the students have been receptive to the different practices and exercises and have been quite participative in the development of all the activities of the course.

The students were pleased with the demonstration sessions of various artistic techniques, as well as with the explanations of small tricks to improve the techniques acquired previously. The students were grateful for the possibility of attending practice sessions outside their usual hours when for some justified reason they could not attend their schedule.

Many of the students have been aware of the relationship between the practices developed and the expressive possibilities of designing, understanding that the process of drawing ideas starts from a mental phenomenon that cannot be compatible with the mere copy of photographed models.

PR1, PR2 and PR3 have had lower scores probably because they are beginners' practices after a long holiday period and because they are facing a change in methodology and proposals with respect to the previous subject (Artistic Expression I), more focused on imitating what is seen than on interpreting it.

However, PR4, PR5 and PR6 have been more stimulating because students develop greater confidence in the use of techniques and expression in sketching.

The practices that are still the most difficult for many of the students to solve are PR8 (vehicles) and PR9 (furniture and interior architecture). It has also been observed that PR7 (toys) has made it difficult to translate objects, perhaps due to the complication of representing circular shapes in perspective (wheels, cylinders, etc.). The new model specially designed for this practice (train of geometric shapes), although it has been well received as an object to draw and represent, has not produced improved results in sketching and its representation in perspective. The models of toys made from pieces obtained from the recovery of discarded plastic bottles have not been sufficiently attractive to students when considering them as models for the development of the practical exercise.

The teamwork for the design of a mascot (PR10) has been enthusiastically received and has served to ease the stress accumulated by the delivery of work in other subjects. The results have probably been somewhat better than in previous years, with more emphasis on the possible mistakes made earlier.

Overall, it is still clear that at the beginning of the course it is difficult for students to adapt to the new proposals for the interpretation and rapid sketching of the objects observed. It is more comfortable to 
copy images of objects than to try to represent the basic lines of form by analyzing and shaping what is seen in real space. Subsequently, a greater degree of confidence and freedom of expression is generated in the practices, although, with the increase in the difficulty of the models proposed in the latest practices, the degree of dissatisfaction in the work carried out also increases and the selfcriticism of the results obtained is aggravated.

The adjustments applied during this course have had an overall positive effect on academic performance. Although the sequence of activities must always be adapted to the particularities of each subject, the results obtained here suggest that the content of the course is appropriate for the development of skills inherent to the industrial designer.

\section{ACKNOWLEDGEMENTS}

The methodologies conducted in this subject are part of the competitive educational improvement project with reference 3398/17, that has received funding from the Educational Support Unit (U.S.E.) of the Universitat Jaume I.

\section{REFERENCES}

[1] M.C. Yang and, J.G. Cham, "An analysis of sketching skill and its role in early stage engineering design", Journal of Mechanical Design, vol. 129, no. 5, pp. 476-482, 2007. Retrieved from http://mechanicaldesign.asmedigitalcollection.asme.org/article.aspx?articleid=1449351

[2] M.J. Eggermont, D.M. Douglas, D.J. Caswell, and C.R. Johnston, "Back to the future: engineering sketching as visualization, idea generation and communication tool" in Proceedings of the Canadian Design Engineering Network Conference, pp. 1-7. Montreal: CEEA, 2004. Retrieved from https://ojs.library.queensu.ca/index.php/PCEEA/article/view/4038

[3] D.G. Ullman, S. Wood and D. Crai, "The Importance of Drawing in the Mechanical Design Process", Computer \& Graphics, vol 14, no. 2, pp. 263-274, 1990. Retrieved from https://www.sciencedirect.com/science/article/pii/009784939090037X?via\%3Dihub

[4] J.L. Navarro Lizandra and F. Felip Miralles, "Improving the understanding of the tridimensionality of the product: new methodologies for the teaching of manual drawing in industrial design" in ICER/2017 Proceedings, 668-672. IATED, 2017 